\title{
The hyperdense lumen sign: the tale of the elusive pulmonary embolism
}

\author{
Nancy Okechukwu, Sheilah M Curran-Melendez, Allison Weyer, Timothy J Mickus
}

Department of Radiology, Allegheny Health Network, Pittsburgh, Pennsylvania, USA

\section{Correspondence to} Dr Nancy Okechukwu, nokechuk@wpahs.org

Accepted 19 October 2014
CrossMark

To cite: Okechukwu N, Curran-Melendez SM,

Weyer A, et al. BMJ Case Rep Published online: [please include Day Month Year] doi:10.1136/bcr-2014205986

\section{DESCRIPTION}

A 55-year-old man with a history of chronic obstructive pulmonary disease (COPD) presented to the emergency department with 2 weeks of progressively worsening dyspnoea. The admitting service interpreted the initial chest radiograph as demonstrating a right lower lobe infiltrate. The patient was admitted for acute COPD exacerbation secondary to right lower lobe pneumonia and was started on antibiotics. An unenhanced chest CT was obtained, which demonstrated hyperdensities within the bilateral pulmonary arteries concerning for pulmonary embolism (PE; figure 1A, B). A chest CT angiography (CTA) was subsequently ordered and confirmed a saddle embolus with multiple bilateral pulmonary emboli (figures $1 \mathrm{C}$ and 2) and right heart strain. The patient's antibiotics were subsequently discontinued and anticoagulation was initiated.

We present a case of the hyperdense lumen sign, a rare finding that has previously been reported to correlate with the presence of acute PE on unenhanced CT with a specificity of $99 \% .{ }^{1}$ The hyperdense appearance of acute thrombus is caused by increased concentration of haemoglobin due to decreased water content and varies based on the patient's haematocrit level and the age of the clot. ${ }^{2}$ However, this finding is rarely observed on unenhanced CT examinations, even when PE is present. There are more well-recognised indirect signs of acute PE, which are neither sensitive nor specific, including pulmonary arterial dilation, pleural effusion, regional oligaemia, subpleural pulmonary consolidations and/or airspace opacities. ${ }^{1}$ In our case, the patient had a dilated main pulmonary artery (figure 2), suggestive of pulmonary

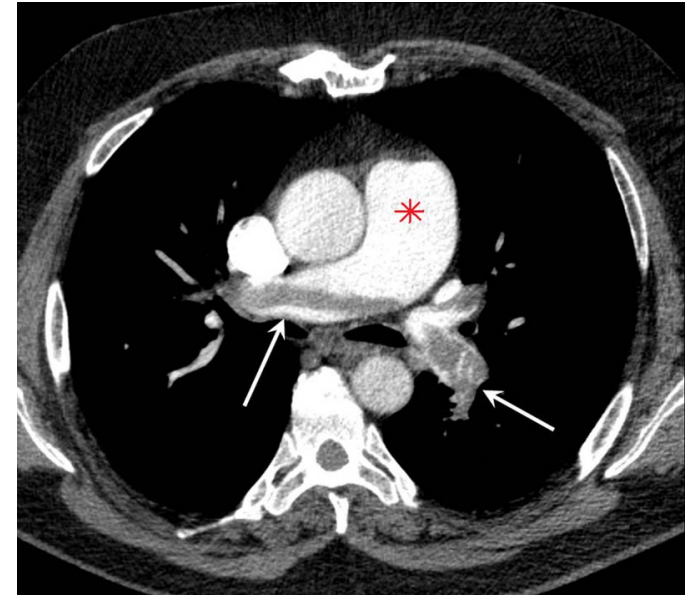

Figure 2 A single axial image from an enhanced CT angiography of the chest demonstrates hypodense filling defects within the bilateral pulmonary arteries (arrows), consistent with acute pulmonary embolism. The main pulmonary artery (asterisk) is dilated.

hypertension and evidence of right heart strain with cor pulmonale confirmed on echocardiogram.

Often, chest CTA is the study of choice for the diagnosis of PE. ${ }^{3}$ However, in situations where PE is not the working clinical diagnosis or the patient is unable to receive intravenous contrast, awareness of the presence of the hyperdense lumen sign on unenhanced CT may contribute to early detection of an acute PE. This was a particularly important finding in our case given the extent of the patient's emboli and associated right heart strain, an indicator of increased mortality risk, leading to the early diagnosis of a potentially fatal condition.
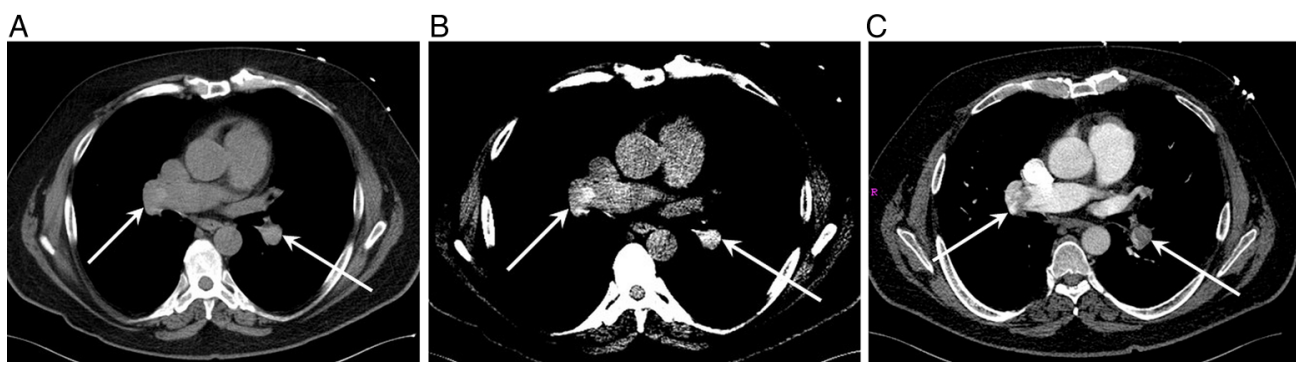

Figure 1 (A) A single axial image from an unenhanced CT of the chest demonstrates hyperdense material present within the bilateral pulmonary arteries (arrows). (B) A single axial image from an unenhanced CT of the chest utilising a narrower window width allows better visualisation of the hyperdense material (arrows). (C) A single axial image from an enhanced CT angiography of the chest demonstrates hypodense filling defects within the bilateral pulmonary arteries (arrows), confirming the findings on the unenhanced CT. 


\section{Learning points}

- The hyperdense lumen sign, a rare occurrence, may serve as an indicator of acute pulmonary embolism on unenhanced CT.

- Acute pulmonary embolism is often a diagnostic challenge for clinicians and awareness of the hyperdense lumen sign may contribute to early diagnosis and appropriate patient management.

- Confirmatory testing with a contrast enhanced chest CT angiography or a V/Q scan is still recommended if a hyperdense lumen sign is identified. ${ }^{3}$
Competing interests None.

Patient consent Obtained.

Provenance and peer review Not commissioned; externally peer reviewed.

\section{REFERENCES}

1 Tatco VR, Piedad $\mathrm{HH}$. The validity of hyperdense lumen sign in the non-contrast chest CT scans in the detection of pulmonary thromboembolism. Int I Cardiovasc Imaging 2011;27:433-40.

2 Kanne JP, Gotway MB, Thoongsuwan N, et al. Six cases of acute central pulmonary embolism revealed on unenhanced multideterctor $C T$ of the chest. $A J R$ 2003;180:1661-4.

3 Sun S, Semionov A, Xie X, et al. Detection of central pulmonary embolism on non-contrast computed tomography: a case control study. Int J Cardiovasc Imaging 2014:30:639-46.

Copyright 2014 BMJ Publishing Group. All rights reserved. For permission to reuse any of this content visit http://group.bmj.com/group/rights-licensing/permissions.

BMJ Case Report Fellows may re-use this article for personal use and teaching without any further permission.

Become a Fellow of BMJ Case Reports today and you can:

- Submit as many cases as you like

- Enjoy fast sympathetic peer review and rapid publication of accepted articles

- Access all the published articles

- Re-use any of the published material for personal use and teaching without further permission

For information on Institutional Fellowships contact consortiasales@bmjgroup.com

Visit casereports.bmj.com for more articles like this and to become a Fellow 